\title{
Improved Assays to Identify the Antibiotic Effects on Planktonic and Sessile Bacteria Using the Example of 1.8-Cineol
}

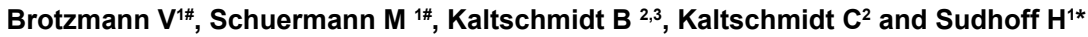 \\ ${ }^{1}$ Department of Otolaryngology, Head and Neck Surgery, Klinikum Bielefeld, 33604 Bielefeld, Germany \\ ${ }^{2}$ Department of Cell Biology, University of Bielefeld, 33619 Bielefeld, Germany \\ ${ }^{3}$ Department of AG Molecular Neurobiology, University of Bielefeld, 33619 Bielefeld, Germany \\ \# Authors contributed equally
}

\begin{abstract}
Screening of antibiotic substances is a mandatory working step during drug development. A variety of methods are available to test their efficiency, they can be divided into diffusion and dilution methods. Diffusion methods in agar based media are rather qualitative approaches, whereas dilution methods, commonly executed in polystyrene microtiter plates, are frequently used to determine the minimal inhibitory concentration (MIC) and the minimal biofilm inhibitory concentration (MBIC $\mathrm{C}_{50}$ ) in a quantitative way. During these standardized assays the physical properties of the agent, e.g. its hydrophobic properties and thermal instability, are often neglected. This study compares different diffusion assays for their sensitivity and improved dilution assays in respect to the thermal sensitivity and the hydrophobic character of antibiotics. We applied 1.8-cineol, a hydrophobic antibacterial component of essential oils, on the pathogen Staphylococcus aureus and investigated the influence of incubation time, cell culture vessels and commonly employed surfactants on the assay. The presented study describes an optimized diffusion assay and a protocol for the exact determination of the $\mathrm{MIC}$ and $\mathrm{MBIC}_{50}$ of thermally instable hydrophobic antibiotic substances. Our assays can be easily executed since they are based on optical density measurements and simple crystal violet staining.
\end{abstract}

We conclude that preliminary screenings of hydrophobic substances can be executed by the well diffusion method. However, for the determination of the MIC and $\mathrm{MBIC}_{50}$ we highly recommend the application of cleaned and etched glass tubes instead of polystyrene cell culture plates. The usage of the surfactants Tween 80 or Tween 20 was found unnecessary and furthermore falsifying the results.

Taken together our improved standard techniques may help to better quantify the antimicrobial potential of hydrophobic antibiotics, e.g. essential oils. This may give new insights into the mode of action and furthermore enable the development of new antimicrobial substances urgently needed to fight resistances against common antibiotics.

Keywords: Minimal inhibitory concentration; Minimal biofilm inhibitory concentration; 1.8-cineol; Hydrophobic antibiotics; Staphylococcus aureus

\section{Introduction}

Human life expectancy has increased in the last century also thanks to the use of antibiotic therapy. Nevertheless, the efficacy of these agents is at stake since their excessive usage has raised resistances of pathogenic bacterial strains against common antibiotics [1]. For this reason, it is becoming increasingly important to find new therapeutic agents with broad-spectrum activities against multi-resistant bacteria [1]. One class of hydrophobic antibacterial agents are essential oils, which have been known for many centuries for their antimicrobial activity $[2,3]$. The mode of action of essential oils on bacterial cells is mainly linked to their hydrophobic nature, prompting them to integrate into the cell membrane resulting in a disruption of bacterial structures and an increase in permeability especially in Gram-positive bacteria $[4,5]$. In this context different essential oils were shown to possess activity against antibiotic-resistant pathogens such as methicillin-resistant Staphylococcus aureus or vancomycin-resistant Enterococcus faecium [6]. Furthermore, different combinations of essential oils and antibiotics were shown to have synergetic effects on different bacterial strains [7]. Since the permeabilizing mode of action of essential oils attacks bacteria on a rather fundamental way, the development of bacterial resistances against this type of substances is unlikely. In this context a study by Becerril et al. reported passaging bacteria up to fifty times in the presence of cinnamon essential oil, indicating no resistance to cinnamon bark oil [8]. Besides the development of resistances to common antibiotics, the treatment of sessile bacterial cells residing in biofilms is a further challenge in the medical treatment of bacterial infections. The National Institutes of Health (NIH) assumed $80 \%$ of all bacterial infections in the human body to be biofilm related especially Staphylococcus aureus (S. aureus) is very common in this context $[9,10]$. Unfortunately, a biofilm cannot be easily penetrated by common antibiotics [11]. Interestingly, Kavanaugh et al. showed that essential oils can eradicate sessile bacteria residing in biofilms with a higher efficiency compared to common antibiotics [12]. Taken together, essential oils seem to be a promising agent to fight antibiotic resistant Gram-positive germs and biofilm formation. For this reason researchers try to explore the seemingly inexhaustible reservoir of natural products as sources of new antimicrobial molecules [13].

*Corresponding author: Sudhoff $\mathrm{H}$, Department of Otolaryngology, Head and Neck Surgery, Klinikum Bielefeld, Teutoburger Str. 50, 33604 Bielefeld, Germany; Tel: 49521 5813301; Fax: 49 5215813399; E-mail: holger.sudhoff@rub.de

Received September 27, 2017; Accepted October 30, 2017; Published October 31, 2017

Citation: Brotzmann V, Schuermann M, Kaltschmidt B, Kaltschmidt C, Sudhoff H (2017) Improved Assays to Identify the Antibiotic Effects on Planktonic and Sessile Bacteria Using the Example of 1.8-Cineol. J Microb Biochem Technol 9:249-256. doi: 10.4172/1948-5948.1000373

Copyright: (c) 2017 Brotzmann V, et al. This is an open-access article distributed under the terms of the Creative Commons Attribution License, which permits unrestricted use, distribution, and reproduction in any medium, provided the original author and source are credited. 
During drug discovery the screening of antibiotic substances for their potential is a mandatory working step. To achieve the most accurate results, physical properties of antibiotic substances, e.g. its hydrophobic characteristics or thermal instability, are features that should be considered during its antimicrobial testing. A variety of methods are available to examine the antimicrobial activity of specific substances. In general the substance of interest is either added in the form of a reservoir in contact to the cultivated bacteria (diffusion test) or diluted directly into the culture media (dilution test) [14]. Diffusion tests are simple and low cost methods to test the efficiency of antimicrobial agents, but gain rather qualitative results. One common diffusion test is the disk-diffusion method developed in $1940[15,16]$. For this assay, sterile filter paper disks with $6 \mathrm{~mm}$ in diameter are saturated with the agent of interest and placed on the surface of the pre-inoculated solid agar. After incubation over night the surrounding of the filter paper disk, displaying inhibited bacterial growth (inhibitory zone), is measured. A further development of this technique is the agar well diffusion method. In this assay wells in an inoculated agar serve as reservoirs for the agent $[14,16]$. The well diffusion method enables the application of higher volumes of the agent and potentially resulting in an increase in sensitivity. In contrast to most antibiotics, essential oils are highly volatile at room temperature. To assay their vapour activity, a paper filter is fixed at the inside of the upper lid of the petri-dish and impregnated with the desired essential oil [17].

The minimum inhibitory concentration (MIC) is defined as the lowest concentration of the antimicrobial agent that inhibits the visible growth. To detect the exact MIC of antimicrobial substances, dilution assays are routinely used [14]. For this method different concentrations of antimicrobial substances were prepared and inoculated with bacteria of usually $1 \times 10^{8} \mathrm{CFU} / \mathrm{ml}$, incubated and afterwards visually checked for turbidity. A more exact approach to determine the bacterial growth is to measure the optical density at $630 \mathrm{~nm}$. Dilution assays offer two advantages compared to diffusion assays. First of all, the exact concentration of the antibiotic agent in the medium can be determined and secondly they are more sensitive since the agent is in direct contact to the microorganism. The parameters mainly affecting the MIC are the incubation time, the type of growth medium as well as the inoculum preparation method. Therefore, the Clinical and Laboratory Standards Institute (CLSI) has standardized the broth dilution method for the testing bacteria [14]. The two common dilution methods are the macrodilution or microdilution incubated a longer time preferably overnight. The macrodilution assay is performed in test tubes or other vessel, which are able to hold a few ml of medium, while the microdilution is executed in polystyrene 96 -well microtiterplates. Due to the obvious advantages of the microdilution assay (prepared panels, economy of reagents and space) nowadays the macrodilution assay is rather rarely utilized [18]. Furthermore, to determine the MIC of essential oils surfactants as Tween 20 or Tween 80 are most often applied to gain a stable emulsion between the culture media and the essential oil [19-23].

To measure the inhibition of biofilm formation by an antimicrobial agent, a microdilution assay as described above, is usually performed. After an incubation of typically $24 \mathrm{~h}$, planktonic cells are removed and the remaining bacteria residing inside the biofilm are stained with crystal violet. The biofilm formation is quantified by solubilisation of the bound crystal violet and spectrophotometric determination of the absorbance at $595 \mathrm{~nm}$ [24]. The biofilm inhibition concentration $\left(\mathrm{MBIC}_{50}\right)$ of an antimicrobial agent is defined as the lowest concentration that showed a $50 \%$ inhibition of the biofilm formation [25]. For essential oils the biofilm formation assay is routinely performed in polystyrene multi-well plates [26-28]
This study demonstrates an improvement to the standard methods utilized to investigate the antimicrobial efficacy of essential oils. For this reason different approaches to determine the antimicrobial potential (MIC and the $\mathrm{MBIC}_{50}$ ) of the Eucalyptus globulus oil compound 1.8-cineol on the Gram-positive bacteria S. aureus (DSM 24167) were investigated, compared and optimized.

\section{Materials and Methods}

\section{Test organism, culture media and 1.8-cineol supplementation}

S. aureus DSM 24167 was obtained from the DSMZ - German Collection of Microorganisms and Cell Cultures $\mathrm{GmbH}$ and stored at $-80^{\circ} \mathrm{C}$ on MicroBank (Mast Group, France) beads until required. Two beads were used for cultivation in $50 \mathrm{ml}$ of Müller Hinton Broth (MHB, Sigma-Aldrich, Germany) overnight at $37^{\circ} \mathrm{C}$ without agitation. 1.8-cineol (supplied by Cassella-med GmbH \& Co. KG, Germany) was aliquoted, stored at $-80^{\circ} \mathrm{C}$ and thawed shortly before it was applied to the medium.

\section{Diffusion assays to determine the antibacterial activity}

The disc diffusion, vapour diffusion and agar well diffusion tests were performed in order to investigate the antibacterial activity of 1.8-cineol against the human pathogenic bacteria S. aureus (DSM 24167). To receive a stock emulsion of $20 \mathrm{mg} / \mathrm{ml} \mathrm{1.8-cineol,} 215 \mu \mathrm{l}$ of 1.8-cineol was diluted in $9.785 \mathrm{ml}$ pure MHB in a glass tube and vortexed vigorously. To compare the sensitivities of the different diffusion assays either pure 1.8-cineol or the emulsions of MHB containing $20 \mathrm{mg} / \mathrm{ml}, 10 \mathrm{mg} / \mathrm{ml}, 5 \mathrm{mg} / \mathrm{ml}, 2.5 \mathrm{mg} / \mathrm{ml}, 1.25 \mathrm{mg} / \mathrm{ml}$ and $0 \mathrm{mg} / \mathrm{ml} \mathrm{1,8-cineol} \mathrm{were} \mathrm{applied} \mathrm{into} \mathrm{the} \mathrm{reservoirs.} \mathrm{The} \mathrm{reservoir}$ containing the undiluted 1,8-cineol was placed on a separate dish while the dilutions were placed altogether on one single dish with exception of the vapour diffusion assay. For all diffusion tests $100 \mu \mathrm{l}$ of overnight culture was diluted 1:100 in MHB and spread onto Müller Hinton nutrient agar plates. To perform the disk diffusion test, sterile paper discs (Liofilchem, Italy) of $6 \mathrm{~mm}$ in diameter were placed on the agar surface and impregnated with $30 \mu \mathrm{l}$ of the fluids described above. To execute the vapor diffusion test sterile filter paper discs with a diameter of $4 \mathrm{~cm}$ containing $100 \mu \mathrm{l}$ of the pure 1.8-cineol or the 1.8 -cineol concentration of $20 \mathrm{mg} / \mathrm{ml}$, were placed separately inside the upper lid of a dish. To conduct the agar well diffusion test small holes with a diameter of $6 \mathrm{~mm}$ were punched aseptically with a sterile tip $(200 \mu \mathrm{l})$ and filled with $100 \mu \mathrm{l}$ of the liquids described above. To prevent evaporation, the plates of every diffusion test were sealed with parafilm (Sigma-Aldrich). After incubation over night at $37^{\circ} \mathrm{C}$, the inhibition zone was determined for each plate.

\section{Determination of the MIC of 1.8-cineol for $S$. aureus in suspension}

To determine the minimal inhibitory concentration (MIC) of 1.8-cineol on planktonic $S$. aureus, a macrodilution assay was performed. This assay was either carried out in 24-well cell culture plates or in glass tubes. The glass tubes were cleaned thoroughly. First physically with a bottlebrush and detergent (Antiseptica, Germany) and subsequently chemically by filling them with $3 \mathrm{ml}$ of $65 \%$ nitric acid and overnight incubation. Just before starting the experiment the overnight culture was adjusted to an $\mathrm{OD}_{630}$ of 0.1 with fresh $\mathrm{MHB}$. To receive a stock emulsion of $20 \mathrm{mg} / \mathrm{ml} \mathrm{1.8-cineol} \mathrm{was} \mathrm{obtained} \mathrm{as} \mathrm{described} \mathrm{above} \mathrm{with} \mathrm{pure} \mathrm{MHB}$ or MHB supplemented with either Tween 20 or Tween 80 . The 1.8-cineol stock was further diluted geometrically to obtain concentrations of 10 $\mathrm{mg} / \mathrm{ml}, 5 \mathrm{mg} / \mathrm{ml}, 2.5 \mathrm{mg} / \mathrm{ml}$ and $1.25 \mathrm{mg} / \mathrm{ml}$. The employed surfactant 
Citation: Brotzmann V, Schuermann M, Kaltschmidt B, Kaltschmidt C, Sudhoff H (2017) Improved Assays to Identify the Antibiotic Effects on Planktonic and Sessile Bacteria Using the Example of 1.8-Cineol. J Microb Biochem Technol 9:249-256. doi: 10.4172/1948-5948.1000373

concentrations were $5 \%, 1 \%, 0.2 \%, 0.04 \%, 0.008 \%$ and $0 \%$. The total culture volume used in wells or tubes was $1 \mathrm{ml}$. Plates and tubes were sealed with parafilm to avoid evaporation of 1.8-cineol and incubated for $6 \mathrm{~h}$ (if not stated otherwise) at $37^{\circ} \mathrm{C}$ without agitation. The MIC was determined spectroscopically at $\mathrm{OD}_{630}$ in biological triplicates. In addition, a visual check for turbidity was performed.

\section{Determination of the $\mathrm{MBIC}_{50}$ of 1.8 -cineol for $S$. aureus biofilm formation}

To determine the minimal biofilm inhibitory concentration $\left(\mathrm{MBIC}_{50}\right)$ of 1.8-cineol on $S$. aureus a modified macrodilution assay was performed. As culture vessels served glass tubes, prepared as described above 2.3 (if not stated otherwise). Three different geometric dilutions were prepared from the $20 \mathrm{mg} / \mathrm{ml} \mathrm{1.8-cineol} \mathrm{stock.} \mathrm{The} \mathrm{concentration}$ series were $20 \mathrm{mg} / \mathrm{ml}, 10 \mathrm{mg} / \mathrm{ml}, 5 \mathrm{mg} / \mathrm{ml}, 2.5 \mathrm{mg} / \mathrm{ml}, 1.25 \mathrm{mg} / \mathrm{ml}$ and $0 \mathrm{mg} / \mathrm{ml} ; 5 \mathrm{mg} / \mathrm{ml}, 2.5 \mathrm{mg} / \mathrm{ml}, 1.25 \mathrm{mg} / \mathrm{ml}, 0.625 \mathrm{mg} / \mathrm{ml}, 0.3125 \mathrm{mg} /$ $\mathrm{ml}, 0 \mathrm{mg} / \mathrm{ml}$ or $0.625 \mathrm{mg} / \mathrm{ml}, 0.3125 \mathrm{mg} / \mathrm{ml}, 0.156 \mathrm{mg} / \mathrm{ml}, 0.078 \mathrm{mg} /$ $\mathrm{ml}, 0.039 \mathrm{mg} / \mathrm{ml}, 0.019 \mathrm{mg} / \mathrm{ml}$ and $0 \mathrm{mg} / \mathrm{ml}$. The media was inoculated with overnight culture to gain an $\mathrm{OD}_{630}$ of 0.1 . The total culture volume used in wells or tubes was $1 \mathrm{ml}$. Plates and tubes were sealed up with parafilm and incubated $24 \mathrm{~h}$ (if not stated otherwise) at $37^{\circ} \mathrm{C}$ without agitation. After the incubation time of $18 \mathrm{~h}$, the 1.8-cineol emulsion was changed. In the case of a prolonged incubation time of $48 \mathrm{~h}$, the 1.8-cineol was changed after $6 \mathrm{~h}, 24 \mathrm{~h}$ and $32 \mathrm{~h}$. After incubation, planktonic cells were removed and the wells or tubes were washed once with phosphate-buffered saline (PBS). To stain the biofilm the crystal violet staining solution ( $0.1 \%$ in distilled water, Sigma-Aldrich) was incubated for ten minutes, followed by three washing steps with distilled water and a visual inspection. To dissolve the dye, $1 \mathrm{ml}$ ethanol was added to the tubes. The $\mathrm{MBIC}_{50}$ was determined spectroscopically at $\mathrm{OD}_{595}$ in biological triplicates.

\section{Oil adsorption assay}

For the qualitative measurement of the oil adsorbed to the polystyrene cell culture wells or glass tubes, a $6 \mathrm{~h}$ incubation was carried out at $37^{\circ} \mathrm{C}$ with an emulsion of MHB and 1,8-cineol as described in section 2.2. The applied concentrations were $20 \mathrm{mg} / \mathrm{ml}, 10 \mathrm{mg} / \mathrm{ml}, 5 \mathrm{mg} / \mathrm{ml}$ and $0 \mathrm{mg} / \mathrm{ml} \mathrm{1.8-cineol}$. Every value was determined as technical triplicate. After incubation the medium was removed and the vessels were washed three times with $\mathrm{ddH}_{2} \mathrm{O}$. The remaining 1.8-cineol was stained by applying a solution of $3 \%$ Sudan red (Sigma-Aldrich) in $90 \%$ acetic acid and $10 \%$ ethanol for 1 min. Subsequently the vessels were washed vigorously with $\mathrm{ddH}_{2} \mathrm{O}$ until no further dye could be detected in the washing solution. The remaining 1.8-cineol, stained with Sudan red and the unspecifically adsorbed dye was solubilized by chloroform. To determine the concentration of Sudan red in the chloroform solution, its OD was measured at 525 and $690 \mathrm{~nm}$.

\section{Thermal treatment of 1.8-cineol}

To verify the thermal instability of 1.8-cineol, a stock of $20 \mathrm{mg} / \mathrm{ml}$ 1.8-cineol dissolved in $\mathrm{MHB}$ was stored at $37^{\circ} \mathrm{C}$ for $24 \mathrm{~h}$. Thereafter, the MIC assay using the broth dilution method was applied, with thermal treated and freshly thawed 1.8-cineol. Finally, the MIC was determined spectroscopically in biological triplicates.

\section{Results}

The antimicrobial activity of 1.8 -cineol can be verified by three different diffusion test methods

To determine the antimicrobial activity of 1.8-cineol on the Grampositive bacteria $S$. aureus (DSM 24167), several diffusion tests were performed. The susceptibility of $S$. aureus to 1.8 -cineol was investigated by the disk diffusion, the vapor diffusion and the agar well diffusion test (Figure 1). The disk diffusion test exhibited an inhibition zone of 11
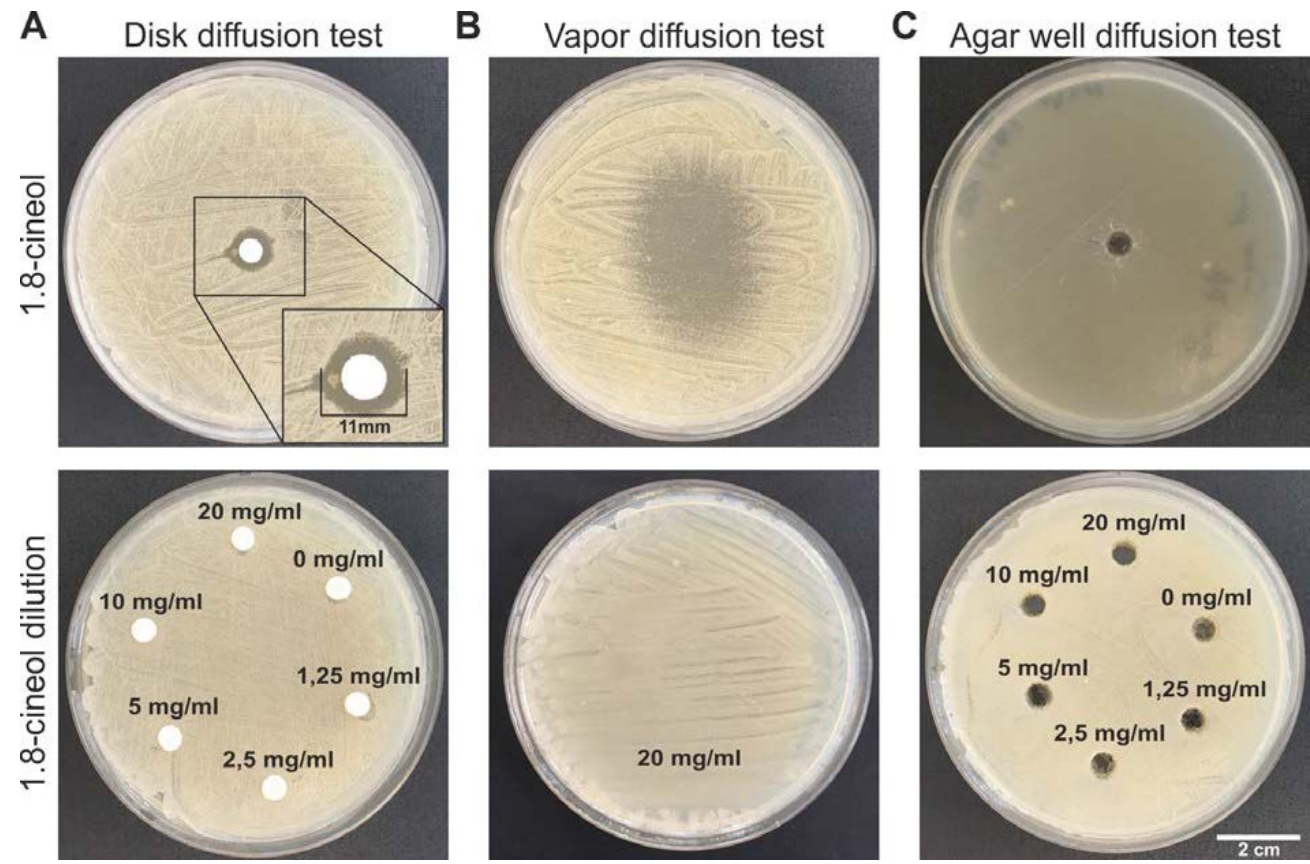

Figure 1: Effect of 1.8-cineol on S. aureus in different diffusion tests. A Effect of pure and diluted 1.8-cineol according to the disk diffusion test. If using pure 1.8-cineol, an inhibition zone of approximately $11 \mathrm{~mm}$ was detected. Filter paper discs moistened with a diluted 1.8-cineol solution resulted in no visible inhibition zones. B The inhibitory effect of the vapour phase of 1.8-cineol in the vapor diffusion test. Using pure 1.8-cineol, an inhibition zone with an average diameter of approximately $3 \mathrm{~cm}$ was visible. No inhibition was found by the use of diluted 1.8 -cineol of $20 \mathrm{mg} / \mathrm{ml}$. C The effect of 1.8-cineol in the agar well diffusion test. In the case of pure $1.8-$ cineol, an inhibition zone appeared to be larger than the agar plate. With diluted 1.8-cineol solutions, no inhibition could be detected. 
Citation: Brotzmann V, Schuermann M, Kaltschmidt B, Kaltschmidt C, Sudhoff H (2017) Improved Assays to Identify the Antibiotic Effects on Planktonic and Sessile Bacteria Using the Example of 1.8-Cineol. J Microb Biochem Technol 9:249-256. doi: 10.4172/1948-5948.1000373

$\mathrm{mm}$ after treatment with pure 1.8-cineol but was not sensitive enough to detect any effect of diluted 1.8-cineol (Figure 1A). In comparison to that, the executed vapor diffusion test showed a greater inhibition zone, if pure 1.8-cineol was applied but likewise the highest 1.8-cineol dilution of $20 \mathrm{mg} / \mathrm{ml}$ showed no inhibition of $S$. aureus (Figure 1B). The agar well diffusion test exhibited the greatest sensitivity of all diffusion tests. If pure 1.8-cineol was applied the inhibition zone exceeded the diameter of the petri dish. However, similar to the results from the other diffusion assays employed, no inhibitory effect was detectable if 1.8-cineol was further diluted (Figure 1C).

\section{The improvement of the macrodilution assay for hydrophobic substances led to the MIC of $5 \mathrm{mg} / \mathrm{ml}$ after $6 \mathrm{~h}$ of incubation.}

In order to determine the MIC of 1.8-cineol against planktonic $S$. aureus, the optimal incubation time for the determination of 1.8-cineol on S. aureus was investigated (Supplementary Figure S1). Compared to $1 \mathrm{~h}$ or $24 \mathrm{~h}$ of incubation the cultures cultivated for 6 $\mathrm{h}$ showed the maximal inhibition and enabled a distinct detection of the MIC. The decrease in inhibitory effect after $6 \mathrm{~h}$ can be explained by the thermic instability of 1.8-cineol. To verify this instability, the biological activity of 1.8-cineol after different thermal treatments was investigated. When 1.8 -cineol was stored for $24 \mathrm{~h}$ at $37^{\circ} \mathrm{C}$ before it was added to the culture, a clear reduction in its antibacterial potential could be detected, if compared to 1.8-cineol that was freshly thawed (Supplementary Figure S2).
Due to these findings further MIC assays were carried out with incubation times of $6 \mathrm{~h}$ in cell culture plates (polystyrene material) and glass tubes (Figure 2). The convenient usage of cell culture plates for the MIC assay exhibited the inhibition of growth at a concentration of $10 \mathrm{mg} /$ $\mathrm{ml}$ (Figure 2A). In contrast, by the use of glass tubes a clear inhibition of bacterial growth at a concentration of $5 \mathrm{mg} / \mathrm{ml}$ was shown. To analyse the cause of the mismatch between the detected MICs, the amount of oil adsorbed to the cell culture plates was qualitatively determined and compared to the oil adsorbed to glass tubes (Supplementary Figure S3). The hydrophobic 1.8-cineol was partly adsorbed to the polystyrene surface of cell culture plates at low concentrations of $5 \mathrm{mg} /$ $\mathrm{ml}$ and largely adsorbed and saturated at a concentration of $10 \mathrm{mg} / \mathrm{ml}$ 1.8-cineol. In contrast to that, 1.8-cineol was not able to adsorb in a detectable amount to glass surfaces. For quick monitoring, it is possible to perform a visual control of bacterial growth (Figure 2D) at any time to observe the course of the experiment.

Many researchers utilize the surfactants Tween 20 or Tween 80 as emulsifiers to stabilize the emulsion of culture media and essential oils. Hence we performed our optimized MIC assay with common concentrations of Tween 20 or Tween 80 with or without the addition $5 \mathrm{mg} / \mathrm{ml} \mathrm{1.8-cineol} \mathrm{(Supplementary} \mathrm{Figure} \mathrm{S4).} \mathrm{An} \mathrm{addition} \mathrm{of} \mathrm{small}$ amount of Tween 20 enhanced the growth, while the addition of higher amount of Tween 20 and 80 lowered the bacterial growth. Remarkably both surfactants were able to reduce the antimicrobial potential of 1.8-cineol even at rather low concentrations.
A

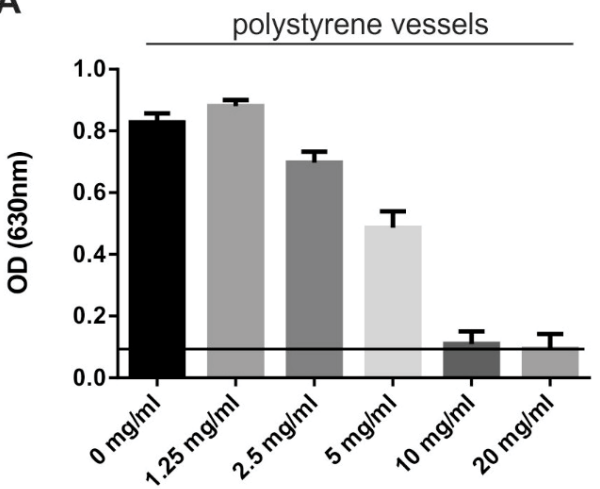

C

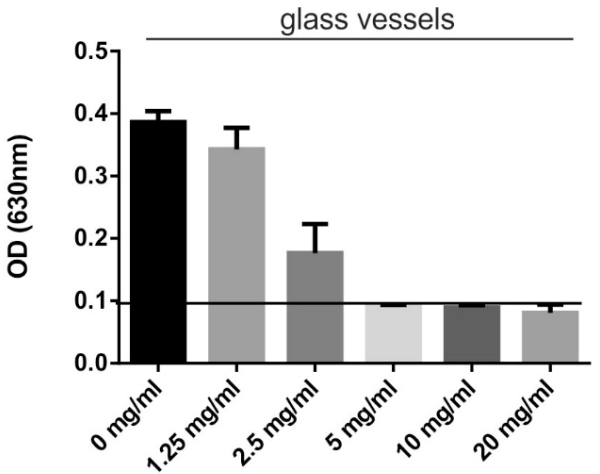

B

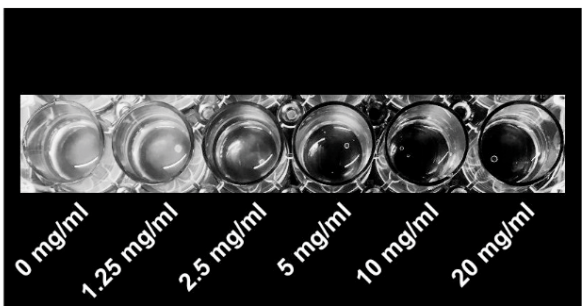

D

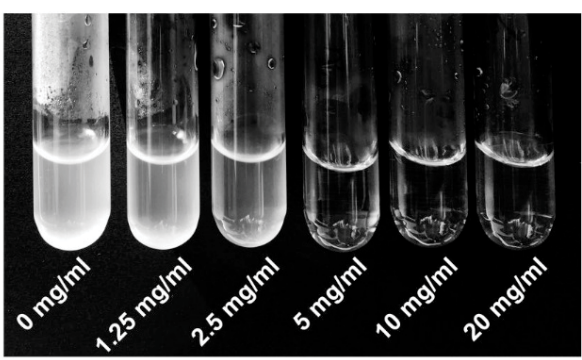

Figure 2: The use of glass vessels results in lower MIC values. A Investigation of the MIC of 1.8-cineol in plastic wells. When using plastic wells, a clear inhibition of growth was detected at a concentration of $10 \mathrm{mg} / \mathrm{ml}$. B Photographic image of the cultures in a polystyrene cell culture plate showing the inhibition by $1.8-$ cineol. Thereby bacterial growth can also be monitored visually during the on-going trial. $\mathbf{C}$ Determination of the MIC of 1.8 -cineol in glass tubes. A significant inhibition of bacterial growth was evident at a concentration of $5 \mathrm{mg} / \mathrm{ml}$. At high concentrations of 1.8-cineol a minimal increase in the $\mathrm{OD}_{630}$ due to light scattered on 1.8 -cineol droplets was observable. Only little inhibition of growth was found at a concentration of $1.25 \mathrm{mg} / \mathrm{ml}$. D Photographic image of the cultures showing the inhibition by 1.8-cineol. By this means bacterial growth can also be monitored visually during the on-going trial. 
Citation: Brotzmann V, Schuermann M, Kaltschmidt B, Kaltschmidt C, Sudhoff H (2017) Improved Assays to Identify the Antibiotic Effects on Planktonic and Sessile Bacteria Using the Example of 1.8-Cineol. J Microb Biochem Technol 9:249-256. doi: 10.4172/1948-5948.1000373

\section{The $\mathrm{MBIC}_{50}$ of 1.8-cineol in glass tubes was observed at a concentration of $0.078 \mathrm{mg} / \mathrm{ml}$}

To determine the $\mathrm{MBIC}_{50}$ of 1.8-cineol against the biofilm formation of $S$. aureus, in vitro tests were performed. The biofilm was localized both, at the bottom of the glass vessel and at the level of the meniscus of the nutrient medium (Supplementary Figure S5A). First, the optimal time period to detect the effect of 1.8-cineol on biofilm formation was analysed in glass tubes (Supplementary Figures S5B-S5D). After an incubation of $6 \mathrm{~h}$, the biofilm was less present compared to $24 \mathrm{~h}$ and the technical triplicates showed a higher variation. Comparing the incubation for $24 \mathrm{~h}$ and $48 \mathrm{~h}$, no increased sensitivity of the assay for the inhibition of biofilm formation was observed and therefore $48 \mathrm{~h}$ seemed not to be suitable for further experiments. Additionally, we compared the biofilm generation on glass and polystyrene surfaces of cell culture wells (Supplementary Figure S6). Even though, the polystyrene showed a high susceptibility for biofilm formation, it is prone to artefacts due to oil adsorption. As a result of these preliminary experiments the detection of $\mathrm{MBIC}_{50}$ of $S$. aureus with different 1.8-cineol concentrations after $24 \mathrm{~h}$ was carried out in glass tubes and cell culture plates (Figure 3 ). In cell culture plates, an even biofilm was formed with a rather high MBIC $_{50}$ of $2.5 \mathrm{mg} / \mathrm{ml} \mathrm{1.8-cineol} \mathrm{(Figure} 3 \mathrm{~A}$ ). In comparison, the formation of biofilm in glass tubes revealed a $\mathrm{MBIC}_{50}$ of less than $1.25 \mathrm{mg} / \mathrm{ml} \mathrm{1.8-cineol} \mathrm{(Figure} \mathrm{3B).} \mathrm{A} \mathrm{further} \mathrm{dilution} \mathrm{of} \mathrm{1.8-cineol}$ exhibited that even at a concentration of $0.3125 \mathrm{mg} / \mathrm{ml}$ (Figure 3C) no build-up or maturation of biofilm could be observed. Final dilution series down to $0.019 \mathrm{mg} / \mathrm{ml}$ elucidated the $\mathrm{MBIC}_{50}$ of 1.8 -cineol against $S$. aureus at $0.078 \mathrm{mg} / \mathrm{ml}$ (Figure 3D).

\section{Discussion}

Methods to judge the efficiency of new antimicrobial agents continue to be developed. Modifications of standard methods are required, if the antimicrobial activity, the MIC or the $\mathrm{MBIC}_{50}$ of hydrophobic or thermally instable agents e.g. essential oils need to be evaluated [14]. Regarding this topic this study was designed to illustrate improvements of common methods to improve the detection of the antimicrobial activity of 1.8-cineol from the Eucalyptus globulus oil against $S$. aureus. We first evaluated the suitability of convenient diffusion tests. Particularly, the disk diffusion, the vapor diffusion and the agar well diffusion test for assaying the antimicrobial activity of 1.8-cineol. One of the frequently used methods for the determination of the MIC of essential oils is the disk diffusion test, a simple and low cost method [16]. Since no inhibition zone could be detected with diluted 1.8-cineol, this test was classified as not sensitive enough to quantify the antimicrobial activity of 1.8 -cineol on $S$. aureus. This is probably due to the fact that the low amount of applied 1.8-cineol either remained on the disc or evaporated and thus did not diffuse into the media [29]. According to Inouye et al. [29], the vapor activity test allowed the application of a higher volume and hence showed a higher sensitivity regarding the antibacterial activity of 1.8-cineol. Anyhow, since the dilution series of 1.8-cineol showed no inhibitory effect in this assay it seems not to be suitable for quantification purposes. Even though the agar well diffusion method showed the highest sensitivity, which is in accordance to a study of Valgas et al. [30], no inhibition could be detected for the diluted 1.8-cineol concentrations.
A

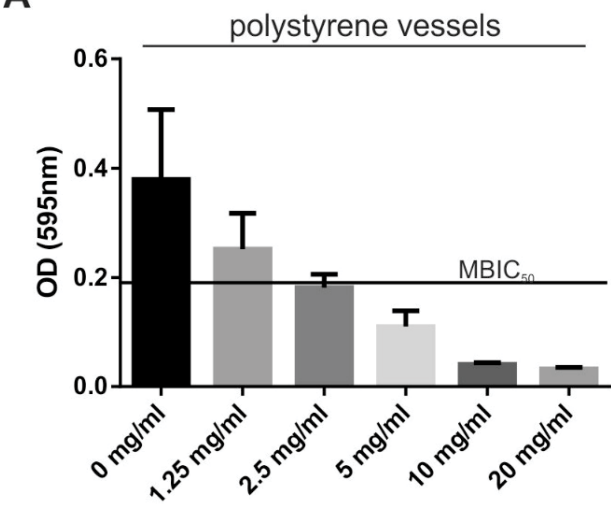

C

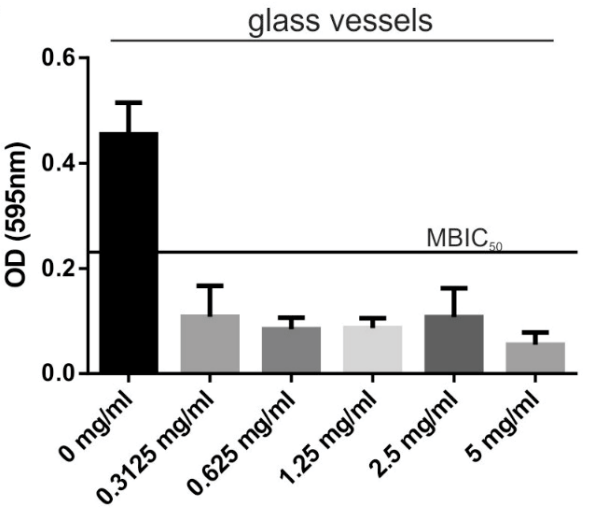

B

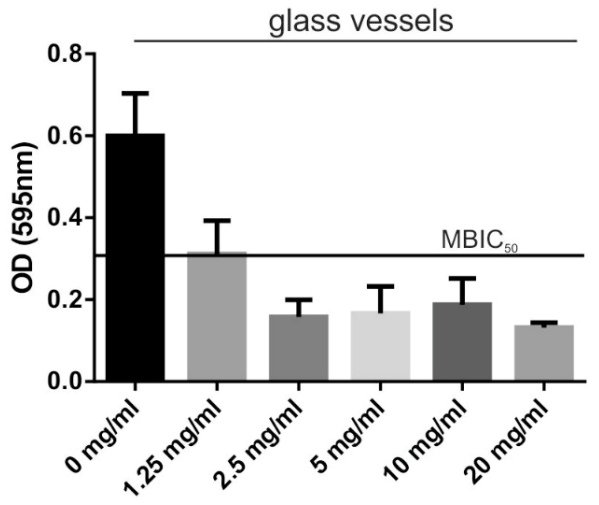

D

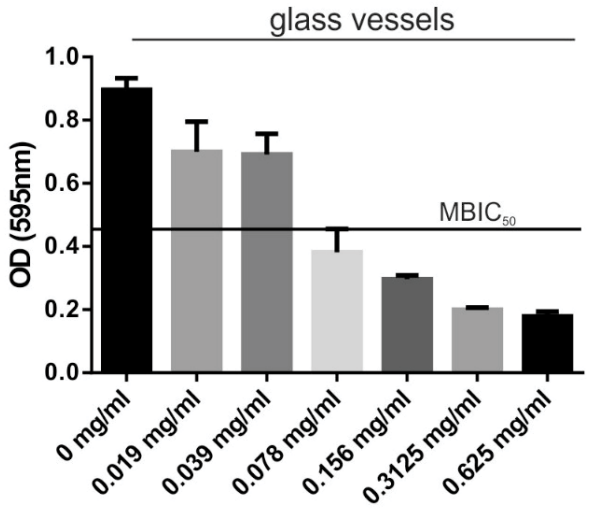

Figure 3: Determination of the $\mathrm{MBIC}_{50}$ of 1.8-cineol on $\mathrm{S}$. aureus biofilms in treated glass results in highly efficient inhibition of biofilm formation in contrast to polystyrene wells. A In plastic wells a uniform biofilm was formed, which showed a $\mathrm{MBIC}_{50}$ of $2.5 \mathrm{mg} / \mathrm{ml} 1.8$-cineol. B In glass tubes the $\mathrm{MBIC}_{50}$ was reduced and detected below $1.25 \mathrm{mg} / \mathrm{ml}$. C Determination of the $\mathrm{MBIC}_{50}$ between $5 \mathrm{mg} / \mathrm{ml}$ and $0.3125 \mathrm{mg} / \mathrm{ml}$. Down to $0.31255 \mathrm{mg} / \mathrm{ml}$ no growth of biofilm could be detected. D Determination of the $\mathrm{MBIC}_{50}$ of biofilm formation from $0.625 \mathrm{mg} / \mathrm{ml}$ to $0.019 \mathrm{mg} / \mathrm{ml}$. This dilution series showed a $\mathrm{MBIC}_{50}$ around $0.078 \mathrm{mg} / \mathrm{ml}$. 
Taken together, our results demonstrate that hydrophobic substances like essential oils or their compounds are not suitable for the diffusion into the agar media. A disadvantage of the diffusion test methods is that the rather long incubation time necessary to detect an inhibition zone. This may lead to evaporation of volatile or the degradation of thermally instable agents. More important, it is not possible to quantify the amount of the antimicrobial agent diffused into the agar medium [14]. Due to the lack in sensitivity and quantifiability of diffusion tests, we would recommend to apply them only to detect the presence or absence of antimicrobial activity and preliminary screening of pure substances [31].

For a more quantitative evaluation we employed the broth dilution method. The broth dilution method is providing a direct contact between essential oils and the test organism. Furthermore the uniform distribution makes the diffusion of agent obsolete [31,32]. The determination of MICs of hydrophobic essential oils is difficult in aqueous medium [33]. Surfactants such as Tween 20 and 80 are commonly used to gain a stable emulsion of essential oils and culture media [34]. A study by Allergini et al. indicated a concentration of 5\% either Tween 80 or Tween 20 to maintain a stable emulsion of essential oils [33]. Hence, many studies designed to determine the efficacy of hydrophobic antimicrobial agents utilized Tween 20 or Tween 80 as an emulsifier with concentrations ranging between $0.1 \%$ and $5 \%$ [34-40]. In contrast, the present study indicated that no emulsifiers are necessary to provide an adequate contact between the oil and the bacteria. Furthermore, we could observe that Tween 20 is able to stimulate the bacterial growth at low concentrations (Supplementary Figure S4A). Even though, we could not observe this effect for Tween 80 , Nielsen and co-workers found that $0.1 \%$ of Tween 80 increases the growth rate of planktonic $S$. aureus and its biomass, if grown as biofilms [41]. The surfactant may affect the nutrient availability by stressing the cells and thereby facilitating a higher nutritional uptake from the culture media [42]. More importantly, we observed Tween 80 and Tween 20 to enable planktonic bacterial growth in attendance of $5 \mathrm{mg} /$ $\mathrm{ml}$ 1.8-cineol (Supplementary Figure S4). It is known that Tween 80 can reduce the efficacy of hydrophobic substances probably by enclosing the hydrophobic antibacterial agent into micelles (Interactions between components of the essential oil of Melaleuca alternifolia) [41,42]. Considering our data we would recommend to spare the usage of these emulsifiers while investigating the antimicrobial activity of 1.8-cineol or other hydrophobic substances to prevent artefacts.

Furthermore, the thermal instability of the tested antimicrobial agents should be considered as well. We found that 1.8-cineol loses its antimicrobial potential after prolonged incubation at $37^{\circ} \mathrm{C}$ (Supplementary Figure S2). The National Committee for Clinical Laboratory Standards (NCCLS) recommends incubating dilution assays for $24 \mathrm{~h}$. Moreover, this time span is also applied by most researchers [43-45]. In contrast to that we would recommend to use an incubation time of just $6 \mathrm{~h}$. Since it would be sufficient to enable a bacterial accumulation, easily distinguishable from inhibited growth, while on the same time preventing decomposition of agents leading to artificially low antimicrobial potential.

Another defining factor during determination of the MIC is the material of the culture vessels. As mentioned by Hammer et al. [46] and Brand et al. [47], hydrophobic components of the tee tree oil may becoming irreversible associated with the polystyrene of e.g. the microtiter plate and hence would not be longer accessible to the test organisms (Supplementary Figure S3) [46,47]. Nevertheless, the application of microdilution assays executed in microtiterplates is recommended by the NCCLS and is still very common $[43,44]$. This is mainly due to the economy of reagents and space to determine the MIC of essential oils. Macrodilution assays are rarely utilized because of the tedious preparation of test tubes and media [18]. With our optimized assay executed in glass tubes, we were able to detect a MIC of $5 \mathrm{mg} /$ $\mathrm{ml} \mathrm{1.8-cineol} \mathrm{for} S$. aureus, in contrast to $10 \mathrm{mg} / \mathrm{ml} \mathrm{measured} \mathrm{for}$ polystyrene culture wells. Other studies detected a MIC of 1.8-cineol at $16 \mathrm{mg} / \mathrm{ml}$ and $20 \mathrm{mg} / \mathrm{ml}$, both studies were executed with microdilution assays in polystyrene microtiter plates $[48,49]$. We conclude that glass vessels should be used to investigate the MIC of 1.8-cineol or other hydrophobic agents even though the convenience of commercially available well plates might be tempting. In this manner it is possible to enlighten the high antimicrobial potential of 1.8-cineol.

Due to the oil adsorption properties of the polystyrene material discussed above, glass tubes needed to be employed to determine the MBIC $_{50}$ of 1.8-cineol of S. aureus (Figures 3A and 3B). Even though, artefacts due to oil adsorption are suppressed in this manner the disadvantage of this procedure is the weak adherence of bacterial cells on glass associated with a poor biofilm formation. To solve this problem Pratten et al. coated glass surfaces with fibronectin and demonstrated an increased adherence of $S$. aureus compared to uncoated glass [50]. Anyhow, we observed an increased biofilm growth, if the glass surface was treated with $65 \%$ nitric acid (Supplementary Figure S6). It is known, that chemically etching of glass with nitric acid increases its roughness [51]. Since one of the main criteria for microbial adhesion to glass is the surface roughness, we suggest the etched glass is more susceptible for biofilm formation $[52,53]$. Even though a prolonged incubation time would lead to a further build-up of biofilm, we found $24 \mathrm{~h}$ to be long enough to detect the inhibitory biofilm maturation with the greatest sensitivity (Supplementary Figure S5) [54]. In the light of the thermal decomposition of agents like 1.8-cineol, we would recommend to incubate biofilm assays for just $24 \mathrm{~h}$, if determining the $\mathrm{MBIC}_{50}$

Our obtained results indicated an inhibition of bacterial cell attachment and biofilm maturation on the cleaned and etched glass surface in the presence of 1.8-cineol. With this setup a $\mathrm{MBIC}_{50}$ of 0.078 $\mathrm{mg} / \mathrm{ml} \mathrm{1.8-cineol} \mathrm{was} \mathrm{verified} \mathrm{for} S$. aureus (Figure 3D). Ghellai et al. demonstrated essential oils to inhibit bacterial biofilm growth of $S$. aureus at a concentration of $1 \mathrm{mg} / \mathrm{ml}$ [55]. Accordingly, we observed a high antimicrobial potential of 1.8-cineol as it has prevented the formation of a biofilm at a very low concentration. Remarkably we found that at a concentration of $0.3 \mathrm{mg} / \mathrm{ml} 1.8$-cineol no growth of biofilm was observable (Figure 3C). Since this value is not even a tenth of the detected MIC, we suggest that 1.8-cineol is able to disturb bacterial sensing, necessary for biofilm formation rather than just inhibit the bacterial growth inside the biofilm.

\section{Conclusion}

In summary, we think that to estimate the presence or absence of antimicrobial activity of essential oils, preliminary screenings using diffusion methods, like the disk diffusion or the agar well diffusion method can be utilized. However, for the determination of the minimal inhibitory concentration we recommend to use the broth dilution method in clean glass tubes treated with nitric acid with short incubation times around $6 \mathrm{~h}$. We found that the use of surfactants Tween 80 or 20 is not necessary and furthermore can artificially influence the measured antimicrobial activity. To determine the $\mathrm{MBIC}_{50}$, we recommend using the same pre-cleaned and etched glass tubes as for determination of the MIC. This will guarantee an adequate attachment of bacterial cells and efficient formation of a biofilm. Furthermore, the incubation time of 24 
Citation: Brotzmann V, Schuermann M, Kaltschmidt B, Kaltschmidt C, Sudhoff H (2017) Improved Assays to Identify the Antibiotic Effects on Planktonic and Sessile Bacteria Using the Example of 1.8-Cineol. J Microb Biochem Technol 9:249-256. doi: 10.4172/1948-5948.1000373

$\mathrm{h}$ is sufficient and a single replacement of agent might be necessary in the case of thermally unstable agents. These improvements of standard microbial methods may help to better quantify the antimicrobial potential of hydrophobic antibiotics and essential oils in particular. This may give new insight into the mode of action of agents and could lead to necessary new discoveries on the vast field of potential antimicrobial agents harbouring enormous potential for the discovery of alternatives to common antibiotics.

\section{Acknowledgement}

We would like to thank Cassella-med GmbH \& Co. KG for providing 1.8-cineol and funding this study. Furthermore, we would like to recognise the great technical assistance of Anja Zielinski, Angela Krahlemann-Köhler and Marcel Kremser.

\section{References}

1. Yap PS, Yiap BC, Ping HC, Lim SH (2014) Essential oils, a new horizon in combating bacterial antibiotic resistance. Open Microbiol J 8: 6-14.

2. Kalemba D, Kunicka A (2013) Antibacterial and antifungal properties of essential oils. Curr Med Chem10: 813-829.

3. Bakkali F, Averbeck S, Averbeck D, Idaomar M (2008) Biological effects of essential oils - A review. Food Chem Toxicol 46: 446-475.

4. Nazzaro F, Fratianni F, De Martino L, Coppola R, De Feo V (2013) Effect of essential oils on pathogenic bacteria. Pharmaceuticals (Basel) 6: 1451-1474.

5. Burt S (2004) Essential oils: Their antibacterial properties and potential applications in foods: A review. Intern J food Microbiol 94: 223-253.

6. Nelson RR (1997) In vitro activities of five plant essential oils against methicillinresistant Staphylococcus aureus and vancomycin-resistant Enterococcus faecium. J Antimicrob Chemother 40: 305-306.

7. Langeveld WT, Veldhuizen EJ, Burt SA (2014) Synergy between essential oil components and antibiotics: A review. Crit Rev Microbiol 40: 76-94.

8. Becerril R, Nerín C, Gómez-Lus R (2012) Evaluation of bacterial resistance to essential oils and antibiotics after exposure to oregano and cinnamon essential oils. Foodborne Pathog Dis 9: 699-705.

9. Davies D (2003) Understanding biofilm resistance to antibacterial agents. Nat Rev Drug Discov 2: 114-122.

10. Manner S, Goeres DM, Skogman M, Vuorela P, Fallarero A (2017) Prevention of Staphylococcus aureus biofilm formation by antibiotics in 96-microtiter well plates and drip flow reactors: Critical factors influencing outcomes. Sci Rep 7 : 43854

11. Stewart PS (2002) Mechanisms of antibiotic resistance in bacterial biofilms. Int J Med Microbiol 292: 107-113.

12. Kavanaugh NL, Ribbeck K (2012) Selected antimicrobial essential oils eradicate Pseudomonas spp. and Staphylococcus aureus biofilms. Appl Environ Microbiol 78: 4057-4061.

13. Brown DG, Lister T, May-Dracka TL (2014) New natural products as new leads for antibacterial drug discovery. Bioorg Med Chem Lett 24: 413-418.

14. Balouiri M, Sadiki M, Ibnsouda SK (2016) Methods for in vitro evaluating antimicrobial activity: A review. J Pharma Anal 6: 71-79.

15. Heatley NG (1944) A method for the assay of penicillin. Biochem J 38: 61-65.

16. Das K, Tiwari R, Shrivastava D (2010) Techniques for evaluation of medicinal plant products as antimicrobial agents: Current methods and future trends. J Med Plants Res 4: 104-111.

17. Inouye S, Takizawa T, Yamaguchi H (2001) Antibacterial activity of essential oils and their major constituents against respiratory tract pathogens by gaseous contact. J Antimicrob Chemother 47: 565-573.

18. Reller LB, Weinstein M, Jorgensen JH, Ferraro MJ (2009) Antimicrobial susceptibility testing: A review of general principles and contemporary practices. Clin Infect Dis 49: 1749-1755.

19. Mann C, Markham J (1998) A new method for determining the minimum inhibitory concentration of essential oils. J Appl Microbiol 84: 538-544.

20. Hammer KA, Carson C, Riley T (1999) Antimicrobial activity of essential oils and other plant extracts. J Applied microb 86: 985-990.
21. Hammer KA, Carson CF, Riley TV (1998) In vitro activity of essential oils, in particular Melaleuca alternifolia (tea tree) oil and tea tree oil products, against Candida spp. J Antimicrob Chemother 42: 591-595.

22. Prabuseenivasan $S$, Jayakumar $M$, Ignacimuthu $S$ (2006) In vitro antibacterial activity of some plant essential oils. BMC Complement Altern Med 6: 39.

23. Celiktas OY, Kocabas EH, Bedir E, Sukan FV, Ozek T et al. (2007) Antimicrobia activities of methanol extracts and essential oils of Rosmarinus officinalis depending on location and seasonal variations. Food Chem 100: 553-559.

24. Stepanovic S, Vukovic D, Hola V, Di Bonaventura G, Djukic SM et al. (2007) Quantification of biofilm in microtiter plates: Overview of testing conditions and practical recommendations for assessment of biofilm production by Staphylococci. APMIS 115: 891-899.

25. Chaieb K, Kouidhi B, Jrah H, Mahdouani K, Bakhrouf A (2011) Antibacteria activity of Thymoquinone, an active principle of Nigella sativa and its potency to prevent bacterial biofilm formation. BMC Complement Altern Med 11: 29.

26. Cosentino S, Tuberoso Cl, Pisano M, Satta V, Mascia et al. (1999) In vitro antimicrobial activity and chemical composition of Sardinian Thymus essential oils. Lett Appl Microbiol 29: 130-135.

27. Schillaci D, Arizza V, Dayton T, Camarda L, Di Stefano V (2008) In vitro antibiofilm activity of Boswellia spp. oleogum resin essential oils. Lett Appl Microbio 47: 433-438.

28. Niu C, Gilbert ES (2004) Colorimetric method for identifying plant essential oi components that affect biofilm formation and structure. Appl Environ Microbio 70: 6951-6956.

29. Inouye S, Uchida K, Maruyama N, Yamaguchi H, Abe S (2006) A novel method to estimate the contribution of the vapor activity of essential oils in agar diffusion assay. Nihon Ishinkin Gakkai Zasshi 47: 91-98.

30. Valgas C, Souza SMD, Smânia EF, Smânia A (2007) Screening methods to determine antibacterial activity of natural products. Braz J Microbiol 38: 369380 .

31. Rios J, Recio M, Villar A (1988) Screening methods for natural products with antimicrobial activity: A review of the literature. J Ethnopharmacol 23: 127-149.

32. Pellecuer J, Allegrini J, Simeon M, Buochberg D (1976) Huiles essentielles bactericides et fongicides. Revue de l'institut Pasteur de Lyon 9: 135-159.

33. Allegrini J, Buochberg de MS, Maillols H (1973) Emulsions d'huiles essentielles fabrication et applications en microbioloige. Travaux de la Societe de Pharmacie de Montpellier 33: 73-86.

34. Mann CM, Markham JL(1998) A new method for determining the minimum inhibitory concentration of essential oils. J Appl Microbiol 84:538-544.

35. Kim J, Marshall MR, Wei Cl (1995) Antibacterial activity of some essential oil components against five foodborne pathogens. J Agri Food Chem 43: 28392845 .

36. Kim J, Marshall M, Cornell J, Wei C (1995) Antibacterial activity of carvacrol, citral and geraniol against Salmonella typhimurium in culture medium and on fish cubes. J Food Sci 60: 1364-1368.

37. Gaysinsky S, Davidson PM, Bruce BD, Weiss J (2005) Growth inhibition of Escherichia coli 0157: $\mathrm{H} 7$ and Listeria monocytogenes by carvacrol and eugenol encapsulated in surfactant micelles. Journal of Food Protection 68 2559-2566.

38. Joshi RK (2014) Chemical composition and antimicrobial activity of the essential oil of Ocimum basilicum L. (sweet basil) from Western Ghats of North West Karnataka, India. Ancient Science of Life 33: 151.

39. Carson CF, Hammer KA, Riley TV (1995) Broth micro-dilution method fo determining the susceptibility of Escherichia coli and Staphylococcus aureus to the essential oil of Melaleuca alternifolia (tea tree oil). Microbios 82: 181-185.

40. Rattanachaikunsopon P, Phumkhachorn P (2010) Antimicrobial activity of basi (Ocimum basilicum) oil against Salmonella enteritidis in in vitro and in food. Biosci Biotechnol Biochem 74: 1200-1204.

41. Nielsen CK, Kjems J, Mygind T, Snabe T, Meyer RL (2016) Effects of tween 80 on growth and biofilm formation in laboratory media. Front Microbiol 7: 1878

42. Taoka Y, Nagano N, Okita Y, Izumida H, Sugimoto S et al. (2011) Effect of Tween 80 on the growth, lipid accumulation and fatty acid composition of Thraustochytrium aureum ATCC 34304. J Biosci Bioeng 111: 420-424. 
Citation: Brotzmann V, Schuermann M, Kaltschmidt B, Kaltschmidt C, Sudhoff H (2017) Improved Assays to Identify the Antibiotic Effects on Planktonic and Sessile Bacteria Using the Example of 1.8-Cineol. J Microb Biochem Technol 9:249-256. doi: 10.4172/1948-5948.1000373

43. Barry AL, Craig WA, Nadler H, Reller LB, Sanders CC, et al. (1999) Methods for determining bactericidal activity of antimicrobial agents: Approved guideline. NCCLS document M26-A: 19

44. Cockerill FR (2010) Clinical and LS Institute, Performance standards for antimicrobial susceptibility testing: Twentieth informational supplement: Provides updated tables for...M02-A10 and M07-A8: National Committee for Clinical Laboratory Standards.

45. Andrews JM (2010) Determination of minimum inhibitory concentrations. J Antimicrob Chemother 48: 5-16.

46. Hammer K, Carson C, Riley T (2003) Antifungal activity of the components of Melaleuca alternifolia (tea tree) oil. J Applied Microbiol 95: 853-860.

47. Brand C, Ferrante A, Prager R, Riley T, Carson C, et al. (2001) The watersoluble components of the essential oil of Melaleuca alternifolia (tea tree oil) suppress the production of superoxide by human monocytes, but not neutrophils, activated in vitro. Inflam Res 50: 213-219.

48. Hendry E, Worthington T, Conway BR, Lambert P (2009) Antimicrobial efficacy of eucalyptus oil and 1,8-cineole alone and in combination with chlorhexidine digluconate against microorganisms grown in planktonic and biofilm cultures. $J$ Antimicrob Chemother 64: 1219-1225.

49. Zengin $\mathrm{H}$, Baysal $\mathrm{AH}$ (2014) Antibacterial and antioxidant activity of essential oil terpenes against pathogenic and spoilage-forming bacteria and cell structureactivity relationships evaluated by SEM microscopy. Molecules 19:17773-17798.

50. Pratten J, Foster SJ, Chan PF, Wilson M, Nair SP (2001) Staphylococcus aureus accessory regulators: Expression within biofilms and effect on adhesion. Microb Infect 3: 633-637.

51. Jang $H$, Chung $Y$, Whangbo $S$, Kim T, Whang $C$ et al. (2001) Effects of chemical etching with nitric acid on glass surfaces. J Vac Sci Technol A 19: 267-274

52. Carlen A, Nikdel K, Wennerberg A, Holmberg K, Olsson J (2001) Surface characteristics and in vitro biofilm formation on glass ionomer and composite resin. Biomaterials 22: 481-487.

53. Quirynen M, Van der Mei H, Bollen C, Schotte A, Marechal M, et al. (1993) An in vivo study of the influence of the surface roughness of implants on the microbiology of supra-and subgingival plaque. J Dent Res 72: 1304-1309.

54. Wolcott R, Rumbaugh K, James GA, Schultz G, Phillips P, et al. Biofilm maturity studies indicate sharp debridement opens a time-dependent therapeutic window. J Wound Care 19: 320-328.

55. Ghellai L, Hassaine H, Khelil NK, Nas F, Aissaoui N, et al. (2014) Antibacterial efficacy of essential oils of three aromatic plants in combination with povidoneiodine against Staphylococcus aureus grown in biofilm cultures. J Appl Pharm Sci 4 